\title{
Addition of Pyridine to Dye-Sensitized Solar Cell Including Fluorinated Oligomer Gel Electrolyte
}

\author{
Masato Ohmukai', Jun Kyokane ${ }^{2}$ \\ ${ }^{1}$ Department of Electrical and Computer Engineering, Akashi College of Technology, Akashi, Japan \\ ${ }^{2}$ Akashi College of Technology, Akashi, Japan \\ Email: ohmukai@akashi.ac.jp
}

Received 21 August 2014; revised 16 September 2014; accepted 6 October 2014

Copyright (C) 2014 by authors and Scientific Research Publishing Inc.

This work is licensed under the Creative Commons Attribution International License (CC BY). http://creativecommons.org/licenses/by/4.0/

c) (i) Open Access

\begin{abstract}
Fluorinated oligomer gel is suitable to the electrolyte of dye-sensitized solar cell for low cost production. In this article, addition of pyridine was investigated for the purpose of enhancing the short current density. Two kinds of ionic liquids were tested: imidazolium and pyrazolium systems. The two different stages of adding pyridine to the electrolyte were considered and the amount of pyridine was studied. It was found that the electrolyte including pyrazolium ionic liquids to which pyridine was added before the mixing with fluorinated oligomer showed the highest electric conductivity, short current density and open voltage. This resulted in the highest conversion efficiency of $4 \%$. As the amount of pyridine increased, the fill factor and the open voltage were improved at first, and then the short current density increased. If the pyridine was added more, the short current density conversely decreased.
\end{abstract}

\section{Keywords}

Ruthenium Ion Complex, Dye-Sensitized Solar Cell, Fluorinated Oligomer, Gel Electrolyte, Ionic Liquids

\section{Introduction}

The dye-sensitized solar cell attracts much attention because it is based on the completely different mechanism from the conventional the pn junction of semiconductors [1]. The cell consists of three parts, namely, the anode, the cathode and the electrolyte. The cathode includes $\mathrm{TiO}_{2}$ nanoparticles, adsorbing dyes such as Ruthenium complex, deposited on a transparent electrode on a glass plate. The light, incoming through the electrode ab- 
sorbed in the dyes, excites electrons in the dyes to transfer to the electrode. The electrons traveling through the outer circuit come back to the anode or the counter electrode to be injected into the electrolyte for the redox reaction of iodine ions. The ion conduction in the electrolyte is also a key factor for the cell performance.

In early days, the electrolyte consists of a liquid, of which the leakage is a big problem for a long-time use. In order to improve the durability of the cell, the gelation of the liquid electrolyte [2], the introduction of ionic liquids [3] and solid electrolyte [4] have been successively proposed. The electrolyte requires the high ionic conduction and aggregation not to leak out the cell at the same time. Some researchers introduced an electrolyte of a polymer cross linked by a chemical reaction to be like a net holding an electrolyte [5]. Our group have developed fluorinated oligomer gel electrolyte for a second ion battery [6], which has been applied to dye-sensitized solar cell afterwards. The advantage of the fluorinated oligomer gel electrolyte is self-aggregation property without cross linkage between chains. The self-aggregation is achieved based on the two mechanisms. One is the intermolecular attraction force between fluorinated alkyl groups; the other is coulomb attraction between a couple of anion and cation that exist in a molecule. The structure of the aggregation is schematically shown in Figure 1.

We have been studying various aspects of the solar cell with the fluorinated oligomer gel electrolyte. The issues investigated so far are, for example, the $\mathrm{TiO}_{2}$ particle [7], the Pt layer on the anode [8], LiI effect instead of $\mathrm{I}_{2}$ [9], and the introduction of ionic liquids [10], In this article, the addition of pyridine to the electrolyte is considered. Pyridine complex derivatives have been introduced to enhance the cell performance. They are attached to ruthenium dyes and then keep the excited electrons in the dye from flowing back into the electrolyte. This helps to enhance the efficiency of electronic flow into the cathode through the $\mathrm{TiO}_{2}$ layer [11]-[13]. We added pyridine to the electrolyte at the two different steps, and considered the effect on the performance. We also tried two kinds of ionic liquids in the same way and compared the results of the electric conductivity and the cell performance.

\section{Experimental Details}

The forming process of the dye-sensitized solar cell can be divided into three parts: the cathode, the anode, and the electrolyte. At the final stage, the electrolyte was sandwiched between the anode and cathode, and sealed the niche with an epoxy resin. The three parts were prepared as follows:

First, the slurry including $\mathrm{TiO}_{2}$ nanoparticles of 50 to $70 \mathrm{~nm}$ in diameter (offered by Sumitomo Titanium) was mixed for 15 minutes with $\mathrm{P}-25$, the commercially available $\mathrm{TiO}_{2}$ powder, by $5 \mathrm{wt} \%$ of the slurry and polyethylene glycol by the same weight of P-25. And then triton X by $10 \mu \mathrm{l}$ was added and mixed well for 15 minutes in order to enhance the viscosity to become a paste. The paste was spread over a FTO glass plate by a doctor blade method. This was dried and then sintered in a furnace at $450^{\circ} \mathrm{C}$ for half an hour. It was then cooled down to room temperature naturally and soaked in a Ruthenium complex dye diluted with ethanol at $3 \times 10^{4} \mathrm{~mol} / 1$ at $50^{\circ} \mathrm{C}$ for 24 hours.

Second, the anode was prepared in such a way that Pt was deposited on FTO glass by a DC sputtering apparatus. The sputtering time was 3 minutes and 10-nm thick Pt film was obtained [8].

Third, the preparation of the electrolyte is described here. The molecular structure of the fluorinated oligomer is shown in Figure 2. Since the fluorinated oligomer cannot gelate ionic liquids only, the mixture of ionic liquids

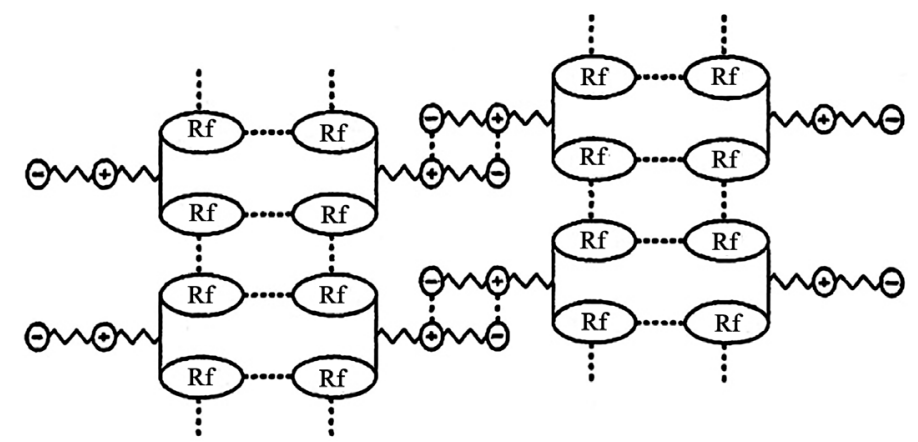

Figure 1. Schematic structure of the aggregation of the fluorinated oligomer. 


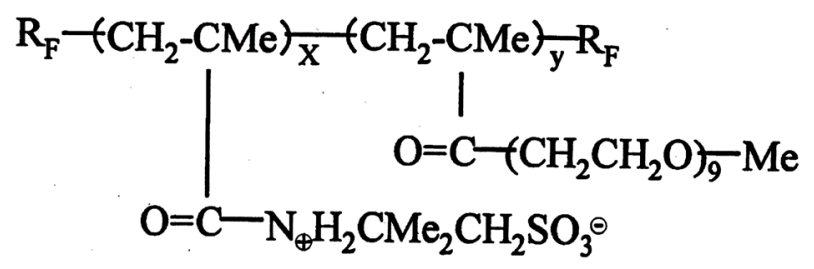

Figure 2. The molecular structure of the fluorinated oligomer.

and dimethyl sulfoxide (DMSO) solved with LiI was used. We used two kinds of ionic liquids: 1-ethyl-3-methylimidazolium trifluoromethanesulfonate (Mi) and 3-methylpyrazolium tetrafluoroborate (Mp). The mixing ratio of DMSO and ionic liquids and the LiI concentration was varied with the type of ionic liquids in order to achieve the highest electric conduction of the obtained electrolyte as reported before [9] [10]. For the Mi case, $15 \mathrm{mmol} / \mathrm{g}$ of LiI was added to DMSO and mixed with $\mathrm{Mi}$ at the volume ratio of Mi:DMSO $=1: 9$. For the Mp case, on the other hand, $5 \mathrm{mmol} / \mathrm{g}$ of LiI was added to DMSO and mixed with Mp at the volume ratio of Mp:DMSO $=3: 7$. The LiI, DMSO and ionic liquids were mixed for 10 to 20 minutes with an ultrasonic agitation. And then the fluorinated oligomer ( $\mathrm{wt} \%$ of the mixture) was added and sonicated for 200 minutes further. The amount of the added oligomer was about $200 \mathrm{~g} / \mathrm{l}$ to the mixture that is a critical concentration for the gelation that had been experimentally found. We tried two kinds of steps of adding pyridine: just before mixing the electrolyte with the fluorinated oligomer (Step 1) and after mixing the electrolyte well with the fluorinated oligomer (Step 2). The amount of added pyridine was $20 \mathrm{wt} \%$ to the electrolyte.

The electrical conductivity of the obtained electrolyte was measured by a Cole-Cole method. The assembled solar cell was examined on J-V characteristics with a varied resistive load between 0 and $20 \mathrm{k} \Omega$ under the exposure of white light from a filtered xenon lamp (AM 1.5) at $55 \mathrm{~mW} / \mathrm{cm}^{2}$. The lamp used in this experiment was UXL500SX by Ushio inc.

\section{Results and Discussion}

The electrical conductivity of each type of the cell is shown in Figure 3. As reported before [9], these kinds of samples showed $16.7 \mathrm{mS} / \mathrm{cm}$ at most without pyridine. From comparing data in Figure 3 with reported data without pyridine, it was confirmed that the electric conductivity was enhanced by adding pyridine in the electrolyte. Mp showed higher conductivity than $\mathrm{Mi}$, and the tendency was consistent with the reported results. It was also found that Step 1 showed higher conductivity than Step 2 in both ionic liquids.

We show the characteristics and performances of the assemble cells in Figure 4 and Figure 5, respectively. From Figure 4, the open voltage is larger for Mp than that for Mi. For each ionic liquid, Step 1 provided the higher open voltage. These tendencies are quite similar to the electric conductivity, though it is hardly understood that the open voltage is directly related to the conductivity of the electrolyte. The short current density behaved a little bit differently. Step 2 showed larger current density in both cases. Step 1 with Mp showed significantly large value of $6.3 \mathrm{~mA} / \mathrm{cm}^{2}$. It was reflected in the performance results shown in Figure 5. The energy conversion efficiency is outstandingly large to be $4 \%$ for the sample of Step 1 with Mp where the other samples showed around $1 \%$. For each ionic liquid, the energy conversion efficiency is the larger for the Step 1 case, but the fill factor is conversely the larger for the Step 2 case.

To summarize these results above, pyridine enhances the open voltage and the short current density at the same time, to improve the energy conversion efficiency for both Mi and Mp ionic liquid. These improvements are more noticeable for the Step 1 treatment than Step 2, except for the fill factor. The difference between the two steps is outstanding for the short current density of the Mp sample, which leads to the conversion efficiency of $4 \%$ as a result. The fact that Step 1 gives better performance of the cell than Step 2 tells us that pyridine cannot entirely permeate into the gel after the electrolyte is gelated with the fluorinated oligomer. We are speculating pyridine plays a key role to form a kind of micro phase separation in the electrolyte.

We next show the dependence of the concentration of pyridine on the J-V characteristics in Figure 6. From 10 to $20 \mathrm{wt} \%$ the open voltage increases and the fill factor is highly improved from 0.48 to 0.64 and saturated for the higher concentration. From 20 to $30 \mathrm{wt} \%$ the current density leaps up significantly. From 30 to $40 \mathrm{wt} \%$ the current density decreases oppositely. We infer that there exist three kinds of effects corresponding to the open voltage increase, the current density increase and current density decrease. Grätzel and co-workers re- 


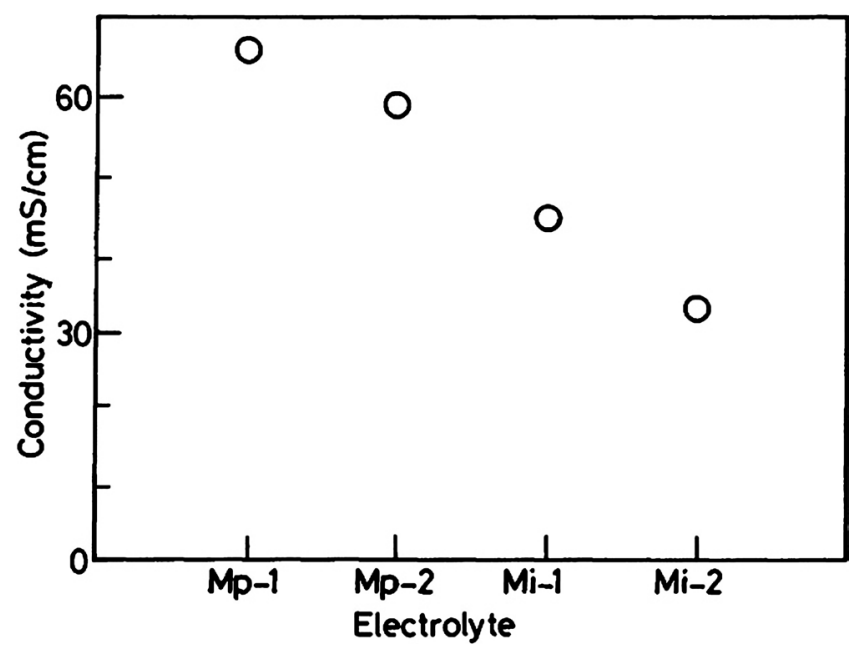

Figure 3. The electric conductivity of the gel electrolyte. It depends on the type of ionic liquids and the step at which pyridine was added. $\mathrm{Mi}$ and $\mathrm{Mp}$ stand for imidazolium and pyrazolium based ionic liquids, respectively. The number 1 or 2 denotes Step 1 or 2 which means the timing of adding pyridine before or after the mixing of fluorinated oligomer, respectively.

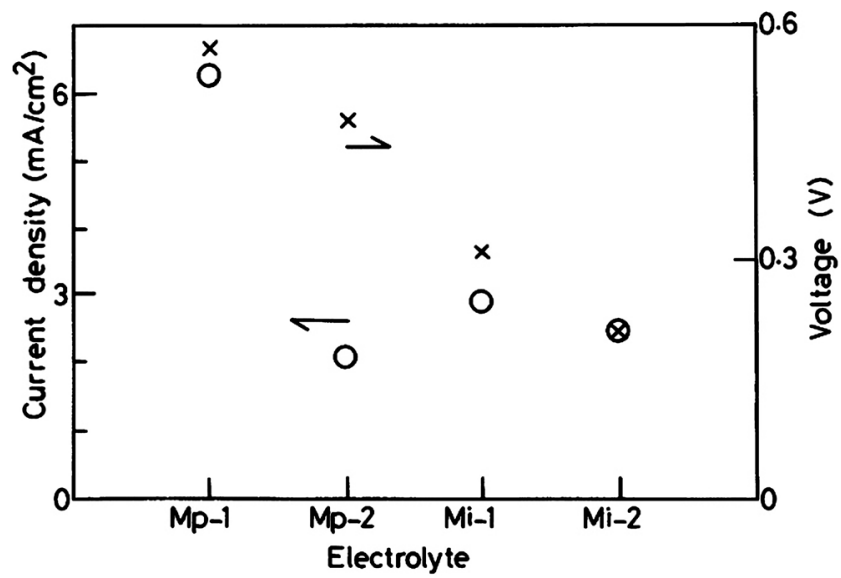

Figure 4. The open voltage and the short current density.

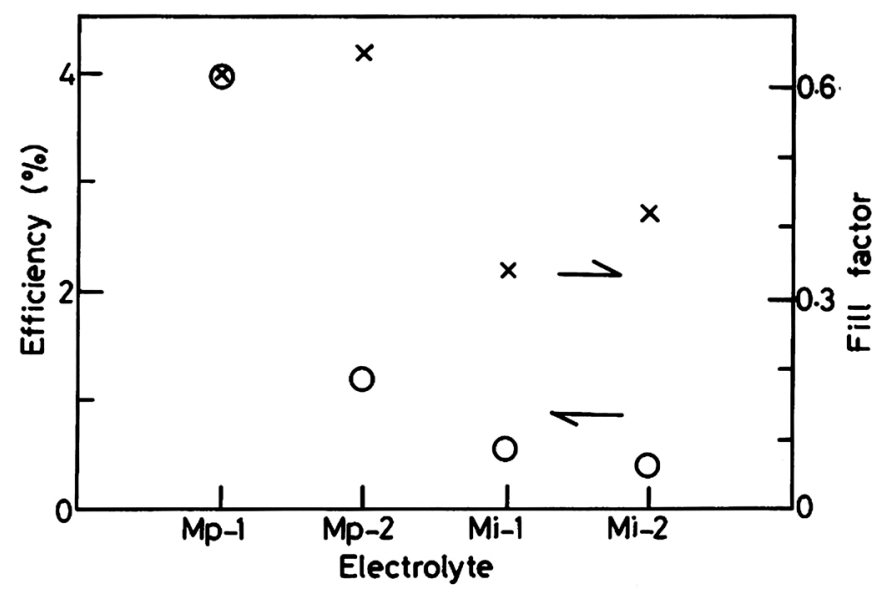

Figure 5. The energy conversion efficiency and the fill factor. 


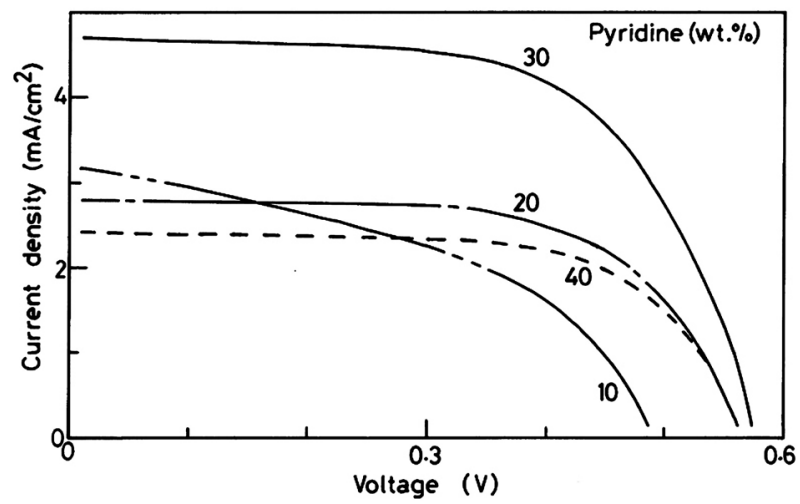

Figure 6. J-V characteristics with a different pyridine concentration.

ported that the addition of 4-tert-butylpyridine into an electrolyte drastically increased the open voltage, the fill factor and conversion efficiency without altering the short current density [14] [15]. The three-step variation of the $\mathrm{J}-\mathrm{V}$ characteristics in our experiment is of interest. It may be a specific phenomenon for the electrolyte gelated with fluorinated oligomer.

In addition, we tried varying the volume ratio of Mp ionic liquid and DMSO including LiI at $5 \mathrm{mmol} / \mathrm{g}$. We obtained the tendency that the short current density decreases as the ratio of ionic liquids increases. The tendency is similar to that reported before without pyridine [10].

\section{Conclusion}

We studied adding pyridine to the electrolyte gelated with fluorinated oligomer. Two kinds of ionic liquids were used in our experiments: imidazolium and pyrazolium systems. We tried two kinds of timing of adding pyridine: (Step 1) after ionic liquids and DMSO with LiI are mixed and before the fluorinated oligomer is added; (Step 2) after the fluorinated oligomer is added and mixed well. Step 1 provided the higher value in the open voltage, the short current density and the energy conversion efficiency together with the higher electric conduction. As the pyridine increases, J-V characteristics vary in three phases: 1) increasing in the open voltage; 2) increasing in the short current density; 3 ) decreasing in the short current density.

\section{References}

[1] O’Regan, B. and Grätzel, M. (1991) A Low-Cost, High-Efficiency Solar Cell Based on Dye-Sensitized Colloidal TiO 2 Films. Nature, 353, 737-740. http://dx.doi.org/10.1038/353737a0

[2] Murai, S., Mikoshiba, S. and Hayase, S. (2007) Influence of Alkyl Dihalide Gelators on Solidification of Dye-Sensitized Solar Cells. Solar Energy Materials and Solar Cells, 91, 1707-1712. http://dx.doi.org/10.1016/j.solmat.2006.12.018

[3] Berginc, M., Krašovec, U.O., Jankovec, M. and Topič, M. (2007) The Effect of Temperature on the Performance of Dye-Sensitized Solar Cells Based on a Propyl-Methyl-Imidazolium Iodide Electrolyte. Solar Energy Materials and Solar Cells, 91, 821-828. http://dx.doi.org/10.1016/j.solmat.2007.02.001

[4] Li, B., Wang, L., Kang, B., Wang, P. and Qiu, Y. (2006) Review of Recent Progress in Solid-State Dye-Sensitized Solar Cells. Solar Energy Materials and Solar Cells, 90, 549-573. http://dx.doi.org/10.1016/j.solmat.2005.04.039

[5] Wei, T.C., Wan, C.C. and Wang, Y.Y. (2007) Preparation and Characterization of a Micro-Porous Polymer Electrolyte with Cross-Linking Network Structure for Dye-Sensitized Solar Cell. Solar Energy Materials and Solar Cells, 91, 1892-1897. http://dx.doi.org/10.1016/j.solmat.2007.07.005

[6] Kyokane, J., Shima, K. and Sawada, H. (2003) Electrical Properties of Fluorinated Gel Electrolytes Using High Ionic Conducting Solution and Its Application to Secondary Battery. Thin Solid Films, 438-439, 257-261. http://dx.doi.org/10.1016/S0040-6090(03)00794-6

[7] Kyokane, J. and Ohmukai, M. (2013) Dye-Sensitized Solar Cell with Fluorinated Gel Electrolyte: Effect of TiO $\mathrm{Par}_{2}$ ticle Size on Performance. Advances in Nanoparticles, 2, 318-322. http://dx.doi.org/10.4236/anp.2013.24043

[8] Ohmukai, M. and Kyokane, J. (2013) Pt Deposition on Anode Enhances the Performance of Dye-Sensitized Solar Cell with Non-Cross-Linked Gel Electrolyte. Journal of Materials Science and Chemical Engineering, 1, 16-19. 
[9] Ohmukai, M. and Kyokane, J. (2013) LiI Enhances the Performance of Dye-Sensitized Solar Cell with Fluorinated Oligomer Gel Electrolyte. Journal of Nano Energy and Power Research, 2, 135-138. http://dx.doi.org/10.1166/jnepr.2013.1018

[10] Ohmukai, M. and Kyokane, J. (2014) The Effect of Ionic Liquid to Dye-Sensitized Solar Cell with Fluorinated Oligomer Electrolyte. Materials Focus, 3, 75-77. http://dx.doi.org/10.1166/mat.2014.1151

[11] Koops, S.E., O’Regan, B.C., Barnes, P.R.F. and Durrant, J.R. (2009) Parameters Influencing the Efficiency of Electron Injection in Dye-Sensitized Solar Cells. Journal of the American Chemical Society, 131, 2808-2818. http://dx.doi.org/10.1021/ja8091278

[12] Yu, S., Ahmadi, S., Sun, C., Palmgren, P., Hennies, F., Zuleta, M. and Göthelid, M. (2010) 4-Tert-Butyl Pyridine Bond Site and Band Bending on $\mathrm{TiO}_{2}$ (110). The Journal of Physical Chemistry C, 114, 2315-2320. http://dx.doi.org/10.1021/jp911038r

[13] Taura, H. and Daiguji, H. (2010) Effect of Pyridine in Electrolyte on the Current-Voltage Characteristics in Dye-Sensitized Solar Cells. Electrochimica Acta, 55, 3491-3496. http://dx.doi.org/10.1016/i.electacta.2010.01.085

[14] Barbe, C.J., Arendse, F., Comte, P., Jirousek, M., Lenzmann, F., Shklover, V. and Grätzel, M. (1997) Nanocrystalline Titanium Oxide Electrodes for Photovoltaic Applications. Journal of the American Ceramic Society, 80, 3157-3171. http://dx.doi.org/10.1111/j.1151-2916.1997.tb03245.x

[15] Huang, S.Y., Schlichthörl, G., Nozik, A.J., Grätzel, M. and Frank, A.J. (1997) Charge Recombination in Dye-Sensitized Nanocrystalline $\mathrm{TiO}_{2}$ Solar Cells. The Journal of Physical Chemistry B, 101, 2579-2582. http://dx.doi.org/10.1021/jp962377q 
Scientific Research Publishing (SCIRP) is one of the largest Open Access journal publishers. It is currently publishing more than 200 open access, online, peer-reviewed journals covering a wide range of academic disciplines. SCIRP serves the worldwide academic communities and contributes to the progress and application of science with its publication.

Other selected journals from SCIRP are listed as below. Submit your manuscript to us via either submit@scirp.org or Online Submission Portal.
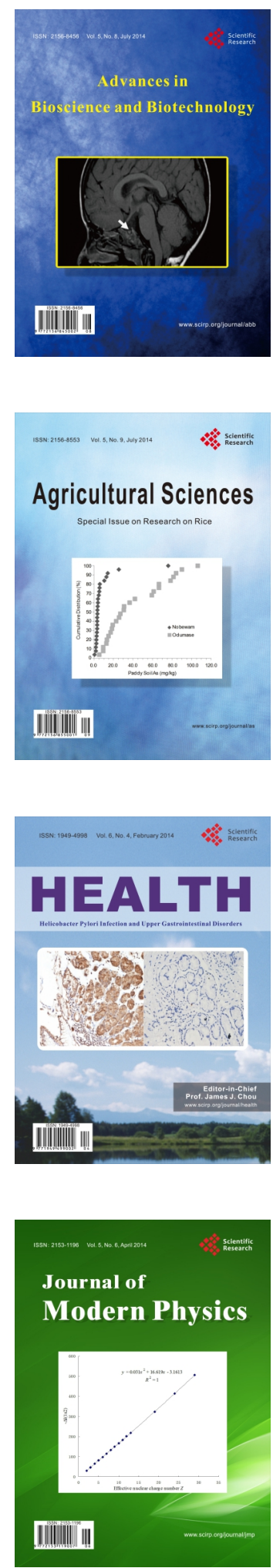
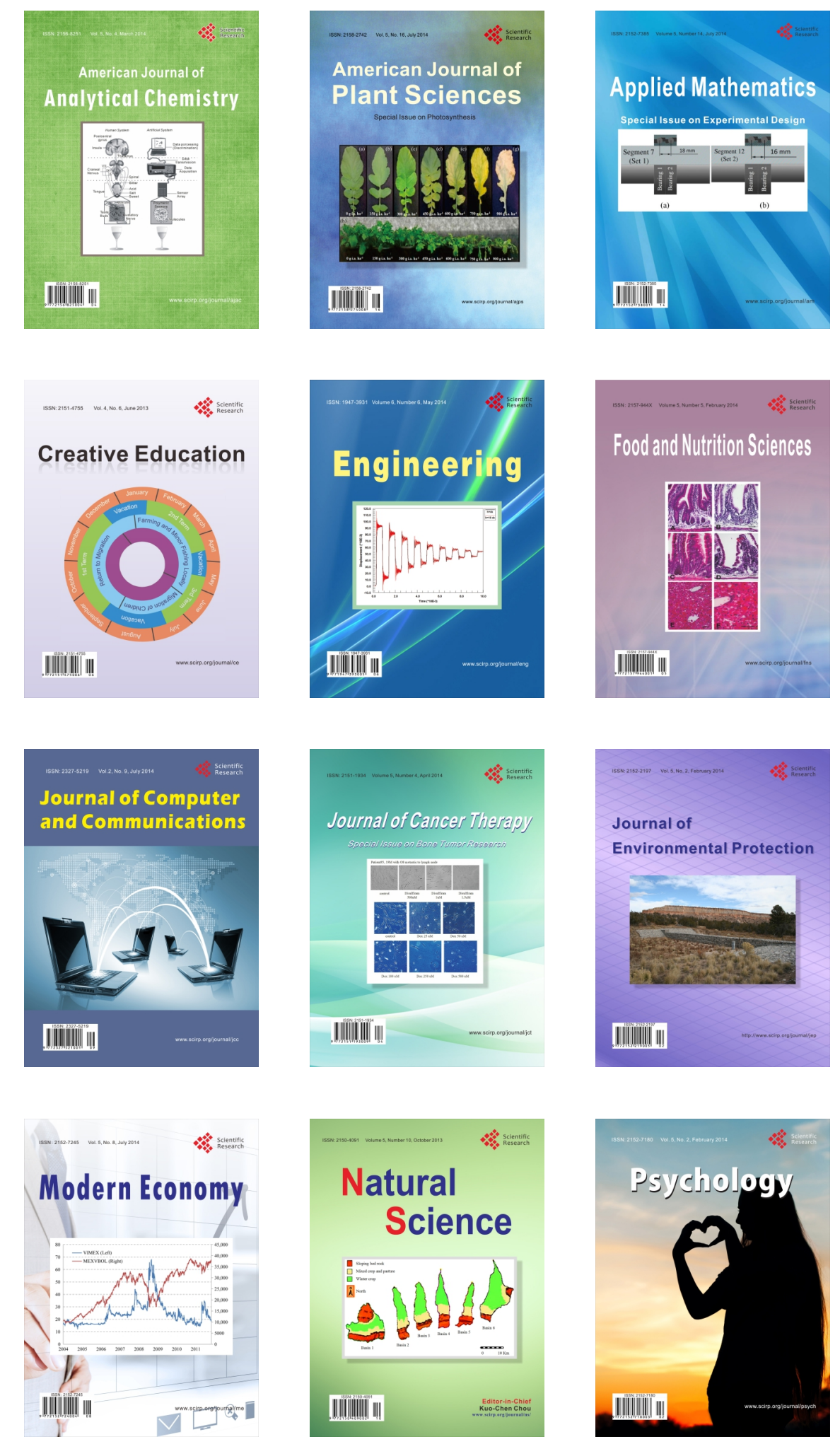